\title{
Expression and prognostic value of epithelial-to-mesenchymal transition and cancer stem cellmarkersin primary lesions and liver metastases of colorectal cancers
}

\author{
CONG LI ${ }^{1,2}$, JI-YAN LIU $^{1}$, DAN JIANG ${ }^{3}$ and MENG QIU ${ }^{1}$ \\ ${ }^{1}$ Department of Medical Oncology, Cancer Center, The State Key Laboratory of Biotherapy, West China Hospital, \\ West China Medical School, Sichuan University, Chengdu, Sichuan 610041; ${ }^{2}$ Department of Radioncology, Chongqing \\ University Cancer Hospital, Chongqing Cancer Institute, Chongqing 400030; ${ }^{3}$ Department of Pathology, West China Hospital, \\ West China Medical School, Sichuan University, Chengdu, Sichuan 610041, P.R. China
}

Received May 21, 2019; Accepted March 22, 2021

DOI: $10.3892 / \mathrm{ol} .2021 .12760$

\begin{abstract}
Cancer stem cells (CSCs) and epithelial mesenchymal transition (EMT) markers are considered useful indicators associated with metastasis and prognosis of colorectal cancers (CRCs). However, only a few studies have focused on the expression of these useful markers in metastases. Metastasectomy is widely used in advanced CRCs, and thus the postoperative prognostic factors are worth investigating. The present study investigated the consistency and differences of target proteins between primary and metastatic lesions of colorectal cancer, and discussed the prognostic indicators following resection of colorectal liver metastases. Clinical data of 56 patients with liver metastases from colorectal cancer were collected and the expression levels of target proteins (Ki-67, CD133, CD44, Snail, E-cadherin and $\beta$-catenin) were detected in primary tumor and matched liver metastases via immunohistochemistry analysis. Paired comparison between both tissue types was performed. The prognostic values of the target proteins for resectable colorectal cancer liver metastases were assessed. No significant differences were observed between the primary tissues and metastatic tissues. The consistency rates of these protein expression levels ranged from 51.8-78.6\%. The maximum diameter of the liver metastases was $<5 \mathrm{~cm}$. Low Snail expression in metastases was associated with a longer overall survival (OS) time following resection of colorectal liver metastases. Furthermore, N0 stage and low carcinoembryonic antigen levels were associated with a longer progression-free survival time. Notably, no significant
\end{abstract}

Correspondence to: Dr Meng Qiu, Department of Medical Oncology, Cancer Center, The State Key Laboratory of Biotherapy, West China Hospital, West China Medical School, Sichuan University, 37 GuoXue Xiang, Chengdu, Sichuan 610041, P.R. China E-mail: qiumeng33@hotmail.com

Key words: epithelial-to-mesenchymal transition, cancer stem cells, primary lesion, liver metastases, prognosis differences were observed in expression levels of the target proteins between the primary tumors and liver metastases. Taken together, the results of the present study suggest that Snail expression in liver metastases may be used as a novel independent prognostic factor for OS following resection of colorectal liver metastases.

\section{Introduction}

Colorectal cancer (CRC) is the most common malignant tumor of the digestive tract, which accounts for $\sim 10 \%$ of the global incidence of cancer and is a serious threat to human health $(1,2)$. The liver is the most common site of metastases, with $50-60 \%$ of patients ultimately developing liver metastases. If untreated, patients with liver metastases from CRC have a poor prognosis, with median survival rates of $<8$ months $(3,4)$. Resection of liver metastases is an important treatment strategy, which improved the 5-year survival rate from 50\% to $60 \%(5,6)$. However, the benefits of liver metastasectomy vary within different patients. Relative predictors are mainly clinical factors but rare valuable biomarkers (7-10).

Metastasis remains a major problem, as such, several studies involving cell culture, animal models and primary cancer tissues have investigated the biological mechanism of metastasis, which is of value to novel interventions for this disease (11-13). Furthermore, several studies have compared primary tumors and metastases (14-17), which may provide novel insights into the topic of metastasis. Epithelial-to-mesenchymal transition (EMT) is a process where epithelial cells acquire the highly invasive and metastatic characteristics of mesenchymal cells, which participate in carcinoma progression, tumor cell invasion and metastasis $(11,18)$. EMT is closely associated with cancer stem cells (CSCs) (19) CSCs and EMT markers, such as CD133 (20), CD44 (21), Snail $(18,22)$, E-cadherin $(18,23)$ and $\beta$-catenin $(18,24)$ are considered useful indicators associated with metastasis and prognosis in several solid tumors. However, only a few studies have investigated the expression differences of these markers between paired primary tumors and metastases (25-28), and their significance in liver metastases from CRCs remains unclear. 
The present study detected and compared the expression levels of CSC and EMT markers in primary colorectal lesions and matched liver metastases. In addition, the prognostic significance of these proteins in primary or metastatic lesions following metastasectomy was investigated.

\section{Materials and methods}

Patient selection. Patients who underwent surgery for both primary CRC and liver metastases between December 2011 and April 2018 at the West China Hospital were enrolled into the present study. The inclusion criterion was the availability of patients' primary and metastatic tumor tissues. The exclusion criteria were as follows: Patients who achieved pathological complete response following neoadjuvant chemotherapy, patients who had other primary tumors or patients with a positive margin. A total of 56 patients were included in the present study. Surgical specimens, including primary tumor tissues and matched metastases were collected in April 2018. The present study was approved by the Ethics Committee of the West China Hospital (approval no. 2017-169) and written informed consent was provided by patients or their family members prior to the study start.

Clinical characteristics and serum indicators at the time of hepatic resection were obtained for subsequent analyses. Patients were prospectively followed-up until February 27, 2019. The median follow-up was 20.6 month (1.0-64.2 months). Progression-free survival (PFS) was the time interval between hepatectomy and the first postoperative disease progression or death. Overall survival (OS) was the time interval between the date of hepatectomy and either the date of death or last follow-up.

Immunohistochemistry. A total ofsix markers, including CD133, CD44 (CSC markers), Snail, E-cadherin, $\beta$-catenin (EMT markers) and Ki-67 (proliferation index) were selected for use in the present study.

Tissue samples were cut into $4-\mu \mathrm{m}$-thick sections, deparaffinized in xylene, dehydrated in a graded ethanol series, placed in ethylenediaminetetraacetic acid buffer ( $\mathrm{pH}$ 8.0) or citrate buffer ( $\mathrm{pH}$ 6.0) for antigen retrieval and immersed in a $0.3 \%$ hydrogen peroxide solution to inhibit endogenous peroxidase activity. Subsequently, tissue sections were incubated with primary antibodies against CD133 (cat. no. MAB4399-I; 1:100; Merck KGaA), CD44 (cat. no. 3570S; 1:100; Cell Signaling Technology, Inc.), Snail (cat. no. ab180714; 1:100; Abcam), E-cadherin (cat. no. 14472S; 1:75; Cell Signaling Technology, Inc.), $\beta$-catenin (cat. no. 8480S; $1: 75$; Cell Signaling Technology, Inc.) and Ki-67 (cat. no. ab15580; 1:400; Abcam) overnight at $4^{\circ} \mathrm{C}$. Following the primary incubation, the sections were washed three times with 0.1 M PBS (pH 7.4) and incubated with PV6001 Two-Step Immunohistochemistry Detection Reagent (ZSJQ-BIO) for $1 \mathrm{~h}$ at $37^{\circ} \mathrm{C}$. The slides were subsequently stained with 3,3'-diaminobenzidine for $3 \mathrm{~min}$ at room temperature and counterstained with $0.1 \%$ hematoxylin for $3 \mathrm{~min}$ at room temperature, washed under running tap water, dehydrated in ethanol and cleared in xylene.

Immunohistochemical evaluations. The expression levels of the antigens were blindly assessed by two investigators using light microscope (at x400 magnification). For CD133 (29), membranous and cytoplasm staining were considered ( $<10 \%$ as low expression vs. $\geq 10 \%$ as high expression). For CD44 (30), only membranous staining was considered ( $<50 \%$ as low expression vs. $\geq 50 \%$ as high expression). For Snail staining (31), nuclear staining was considered $(<1 \%$ as low expression vs. $\geq 1 \%$ as high expression). E-cadherin (32) staining was defined as detectable immunoreactions in cell membranes. The product of the intensity $(0$, negative; 1 , weak and 2 , strong) and percentage $(1,25 \% ; 2,26-50 \% ; 3,51-75 \%$ and $4,76-100 \%)$ was used as the final score (0-1 as low expression vs. 3-8 as high expression). Ki-67 staining was only expressed in the nuclei $(<50 \%$ as low expression vs. $\geq 50 \%$ as high expression). Considering the complexity of $\beta$-catenin expression and the significance of ectopic $\beta$-catenin from the membrane to the nuclei (33), samples were divided into normal and abnormal groups. Abnormal expression was associated with decreased intercellular adhesion and activation of downstream tumor proliferation-related target genes, resulting in tumorigenesis and metastasis (34). Normal expression was defined as positive membranous staining in $\geq 70 \%$ of cells and positive cytoplasmic/nuclear staining in $<10 \%$ of cells. Abnormal expression was considered in the absence of membranous staining or positive membranous staining in $<70 \%$ of cells or positive cytoplasmic/nuclear staining positive in $\geq 10 \%$ of cells.

Statistical analysis. Statistical analysis was performed using SPSS 20.0 (IBM Corp.). Classification data were analyzed using the $\chi^{2}$ and Fisher exact tests. McNemar's test was used for paired data selection, while the rank-sum test was used for nonparametric data and grade variables. Univariate analysis was performed using the Kaplan-Meier method and log-rank test following liver metastasis resection. Multivariate Cox regression analysis was performed to determine the prognostic value. $\mathrm{P}<0.05$ was considered to indicate a statistically significant difference.

\section{Results}

Patient characteristics. A total of 56 patients with primary and secondary CRC were included in the present study. Patient characteristics are summarized in Table I. A total of 46 patients had liver metastases diagnosed at the time of CRC diagnosis or before, of which 16 patients had isolated metastases and 40 patients had multiple lesions (no more than five). A total of 31 patients underwent simultaneous resection of the primary tumor and metastases. A total of 31 patients received neoadjuvant chemotherapy, while 41 patients received adjuvant chemotherapy.

The median follow-up time was 20.6 months, and 18 patients died. At the end of the study, the median OS time following liver metastasectomy was 34.4 months [95\% confidence interval (CI), 28.5-40.2 months; Fig. 1A] and the median PFS time was 11.0 months (95\% CI, 8.4-13.7 months; Fig. 1B).

Primary lesions vs. matched liver metastases. Samples with low quality staining were excluded from the analyses. In the 112 tissue samples, the high expression rates of Ki-67, CD133, CD44, Snail, E-cadherin and $\beta$-catenin were 40.2, 49.1, 16.1, 
Table I. Patient characteristics $(n=56)$.

\begin{tabular}{|c|c|c|c|}
\hline Characteristic & Number of patients, (\%) & Characteristic & Number of patients, (\%) \\
\hline Sex & & Extrahepatic metastases & \\
\hline Male & $36(64.3)$ & With & $10(17.9)$ \\
\hline Female & $20(35.7)$ & Without & $46(82.1)$ \\
\hline Age at diagnosis, years & & Neoadjuvant chemotherapy & \\
\hline$\leq 55$ & $22(39.3)$ & With & $31(55.4)$ \\
\hline$>55$ & $34(60.7)$ & Without & $25(44.6)$ \\
\hline Primary tumor & & Adjuvant chemotherapy & \\
\hline Rectum & $30(53.6)$ & With & $41(73.2)$ \\
\hline Colon & $26(46.4)$ & Without & $15(26.8)$ \\
\hline Pathological type & & $\mathrm{HB}, \mathrm{g} / \mathrm{l}$ & \\
\hline Adenocarcinoma & $45(80.4)$ & $<120$ & $19(33.9)$ \\
\hline Mucinous adenocarcinoma & $11(19.6)$ & $\geq 120$ & $37(66.1)$ \\
\hline Differentiation & & PLT, $x 10^{9} / 1$ & \\
\hline Low & $17(30.4)$ & $<100$ & $6(10.7)$ \\
\hline Moderate & $39(69.6)$ & $\geq 100$ & $50(89.3)$ \\
\hline T stage & & NLR & \\
\hline $\mathrm{T} 1-3$ & $33(58.9)$ & $<2$ & $16(28.6)$ \\
\hline $\mathrm{T} 4$ & $23(41.1)$ & $\geq 2$ & $40(71.4)$ \\
\hline N stage & & ALB, $g / 1$ & \\
\hline No & $19(33.9)$ & $<40$ & $15(26.8)$ \\
\hline N1-2 & $37(66.1)$ & $\geq 40$ & $41(73.2)$ \\
\hline Time of liver metastasis & & LDH, IU/1 & \\
\hline Synchronous & $46(82.1)$ & $<220$ & $45(80.4)$ \\
\hline Metachronous & $10(17.9)$ & $\geq 220$ & $11(19.6)$ \\
\hline $\mathrm{N}$ of liver metastasis & & $\mathrm{CEA}, \mathrm{ng} / \mathrm{ml}$ & \\
\hline One & $16(28.6)$ & $<3.4$ & $11(19.6)$ \\
\hline Multiple & $40(71.4)$ & $\geq 3.4$ & $45(80.4)$ \\
\hline $\begin{array}{l}\text { Maximum diameter of liver } \\
\text { metastases, } \mathrm{cm}\end{array}$ & CA199, U/ml & & \\
\hline$<5$ & $45(80.4)$ & $<22$ & $27(48.2)$ \\
\hline$\geq 5$ & $11(19.6)$ & $\geq 22$ & $29(51.8)$ \\
\hline
\end{tabular}

HB, hemoglobin; PLT, platelet; NLR, neutrophil to lymphocyte rate; ALB, albumin; LDH, lactate dehydrogenase; CEA, carcinoma embryonic antigen; CA199, carbohydrate antigen 199.
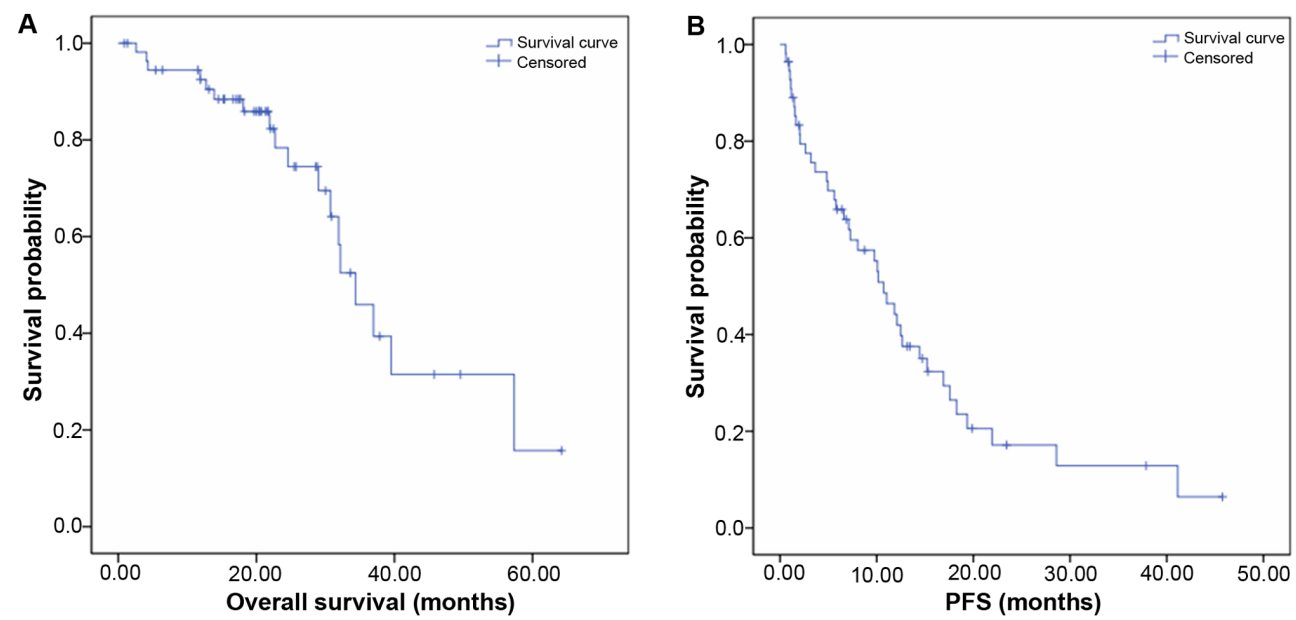

Figure 1. Overall survival and PFS times of patients with colorectal cancer. PFS, progression-free survival. 

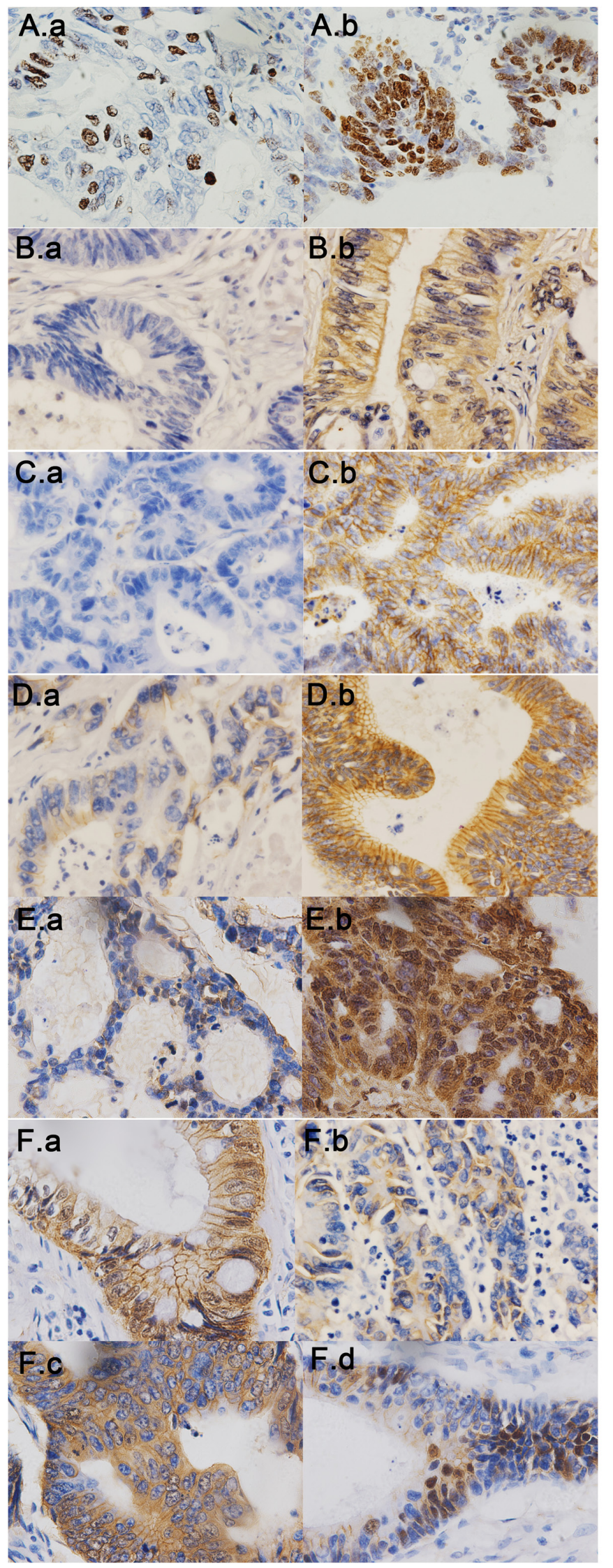

Figure 2. Immunohistochemical staining of (A) Ki-67, (B) CD133, (C) CD44, (D) E-cadherin, (E) Snail and (F) $\beta$-catenin (magnification, $\mathrm{x} 400)$. For (A-E), (a and b) refer to low and high expression, respectively. For (F), (a) refers to normal expression and (b-d) refer to abnormal expression; (b) decreased membranous staining, (c) abnormal cytoplasmic staining and (d) abnormal nuclear staining.
61.6, 48.2 and $76.8 \%$, respectively (Fig. 2). The expression levels of the markers were similar between the primary tumors and matched metastases (Table II), and the consistency rates ranged from 51.8-78.6\%. Among these, CD44 expression was the most similar between the primary tumors and matched metastases (consistency rate of 78.6\%). Consistent with this result, McNemar's test demonstrated no significant difference $\left(\mathrm{P}_{\mathrm{Ki}-67}, 0.541 ; \mathrm{P}_{\mathrm{CD} 133}, 0.248 ; \mathrm{P}_{\mathrm{CD} 44}, 1.000 ; \mathrm{P}_{\text {Snail }}, 0.424\right.$; $\mathrm{P}_{\mathrm{E}-\text { cadherin }}, 1.000$ and $\left.\mathrm{P}_{\beta \text {-catenin }}, 1.000\right)$. In addition, the rank-sum test revealed no significant variation trends between the target proteins ( ${ }_{\mathrm{PKi}-67}, 0.414 ; \mathrm{P}_{\mathrm{CD} 133}, 0.178 ; \mathrm{P}_{\mathrm{CD} 44}, 1.000 ; \mathrm{P}_{\text {Snail }}, 0.317$; $\mathrm{P}_{\mathrm{E} \text {-cadherin }}, 1.000$ and $\left.\mathrm{P}_{\beta \text {-catenin }}, 1.000\right)$.

Clinicopathological characteristics and target proteins. High CD133 expression in primary tumors was significantly associated with tumor location of the colon $(\mathrm{P}=0.013)$, while high CD133 expression in liver metastases was significantly associated with age $(\mathrm{P}=0.003)$ and positive lymph nodes $(\mathrm{P}=0.018)$. Furthermore, Snail expression in liver metastases was significantly associated with more metastases $(\mathrm{P}=0.028)$ and a lower differentiation degree $(\mathrm{P}=0.012)$. No other clinical features were significantly associated with the target proteins (Tables SI-VI).

Clinical outcomes following liver metastasectomy. Kaplan-Meier survival analysis demonstrated that the maximum diameter of liver metastases was $<5 \mathrm{~cm}(\mathrm{P}=0.023$; Fig. 3A) and low Snail expression in metastases was significantly associated with a longer OS time following resection of colorectal liver metastases $(\mathrm{P}=0.029$; Fig. 3B). In addition, N0 stage $(\mathrm{P}=0.021$; Fig. $3 \mathrm{C})$ and low CEA expression $(\mathrm{P}=0.007$; Fig. 3D) were also associated with longer PFS times. Multivariate Cox regression analysis demonstrated that the maximum diameter of liver metastases [hazard ratio (HR), 3.447; 95\% CI, 1.154-10.041; $\mathrm{P}=0.019)$ and Snail expression in liver metastases (HR, 3.405; 95\% CI, 1.225-9.697; $\mathrm{P}=0.026$ ) can be used as independent prognostic factors for OS following resection of colorectal liver metastases (Table III).

\section{Discussion}

EMT is an essential condition for tumor metastasis, which can deprive tumor cells of their adhesive capacity and provide them 'legs' for metastasis throughout the body $(11,35)$. EMT also induce CSCs (36). Although a new study suggested that EMT may not be required for metastasis but contributes to chemoresistance (37), the contribution of CSCs and the EMT metastasis and development theory are still widely accepted, and worth further investigation. CD133, CD44, Snail, E-cadherin and $\beta$-catenin as surface markers reflecting the EMT status and the level of CSCs have been considered reliable indicators $(18,20-24)$. The present study compared the expression levels of these related markers in matched primary and metastatic tumors, and investigated the prognostic values of these EMT and CSC-related biomarkers.

The comparison between primary cancer and matched metastases has always been of great interest to researchers and produced conflicting findings (14). Previous studies have demonstrated high similarities in cytological features $(38,39)$, 
A

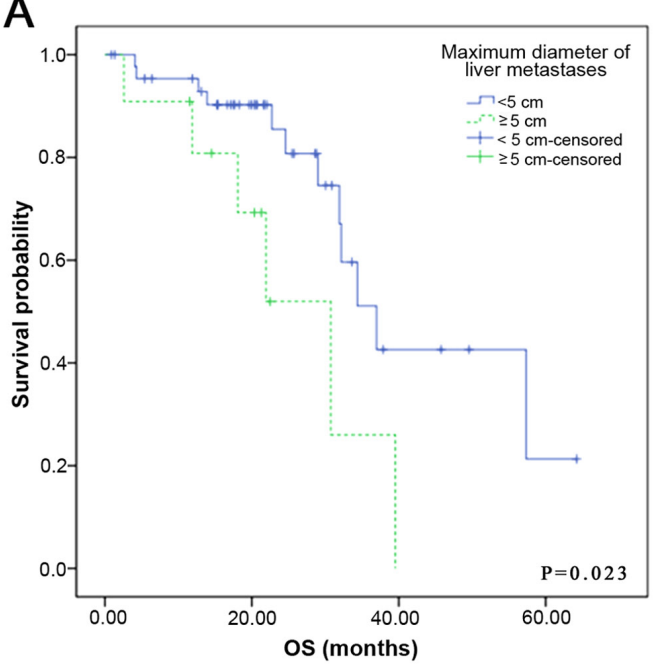

C

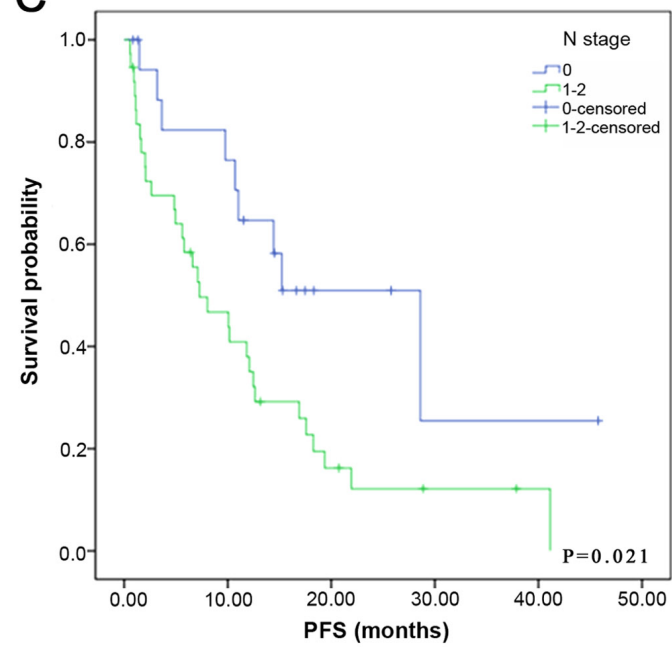

B

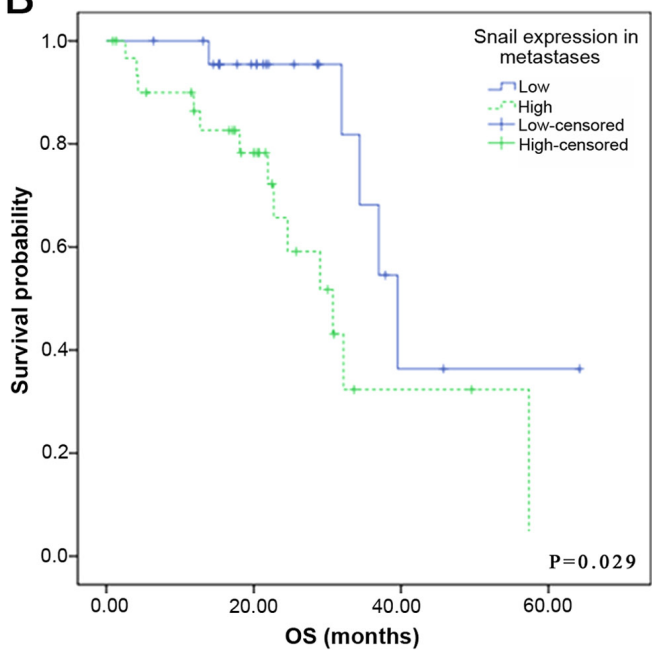

D

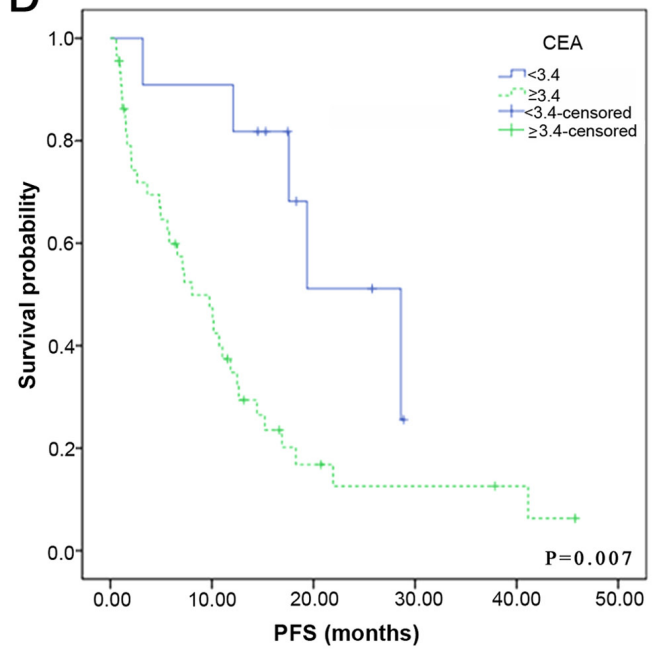

Figure 3. Prognostic factors of clinical outcomes following liver metastasectomy. (A) The maximum diameter of liver metastases and (B) low Snail expression in metastases were associated with OS time. (C) N0 stage and (D) CEA expression were associated with PFS time. OS, overall survival; PFS, progression-free survival.

gene mutation or profile $(17,40,41)$ and protein expression $(16,25)$, suggesting that matched tumors have a common origin and the key biological features of primary tumors are maintained in metastases. These findings are crucial in origin identification of metastases and the choice of suitable treatments, given that it relies on their primary tumors. Conversely, novel traits of metastases have been reported $(15,27)$ that owing to the different secondary site microenvironment, changes for adaptation are required for tumor survival. In the present study, no significant differences in the expression levels of CD133, CD44, Snail, E-cadherin, $\beta$-cateninand Ki-67 were observed between primary tumors and metastatic lesions, which is consistent with most of the literature (16,17,25,38-41). However, previous studies have rarely calculated the consistency rates. Kishikawa et al (25) reported a high degree of consistency rate of CD133 (88.6\%) in primary and metastatic lesions, while a consistency rate of only $51.8 \%$ was demonstrated in the present study. This difference may be due to the different characteristics of metastases.

Another area of interest is the association between the clinicopathological characteristics of patients with CRC and the metastasis-related markers. In the present study, high CD133 expression in the liver metastases was associated with age and positive lymph nodes, which is similar to the previous study on CD133 expression in primary tumors (42). Given that CD133 is a stem cell marker, this suggests that older patients or patients with lymph node metastases may have greater stem cell activity in the metastases, resulting in further deterioration. Snail promotes EMT by inhibiting E-cadherin expression involved in the transformation of epithelial cells to mesenchymal cells and its expression in primary canceris associated with invasive and metastatic abilities (22). Even in liver metastases, the present study demonstrated that snail expression exhibited an association between metastases and a low degree of differentiation.

The association between EMT or CSC-related biomarkers was investigated in patients with resectable liver metastases. Over the past 20 years, there have been more than 10types of CRC liver metastases prognosis risk clinical score systems $(7,8)$. such as the Nordlinger score (9) and MSKCC score (10). In addition, some biomarkers, such as KRAS and BRAF gene mutations (43), have been reported as potential factors of postoperative prognosis. The present study analyzed 
Table II. Expression levels of target proteins between primary tumors and matched metastases.

\begin{tabular}{lccrcc}
\hline Target protein & $\begin{array}{c}\mathrm{P}=\mathrm{M}, \\
\mathrm{n}(\%)\end{array}$ & $\begin{array}{c}\mathrm{P}<\mathrm{M}, \\
\mathrm{n}(\%)\end{array}$ & $\begin{array}{c}\mathrm{P}>\mathrm{M}, \\
\mathrm{n}(\%)\end{array}$ & $\begin{array}{c}\text { McNemar's test } \\
\text { P-value }\end{array}$ & $\begin{array}{c}\text { Rank-sum test } \\
\text { P-value }\end{array}$ \\
\hline Ki-67 & $32(57.1)$ & $10(17.9)$ & $14(25.0)$ & 0.541 & 0.414 \\
CD133 & $29(51.8)$ & $10(17.9)$ & $17(30.4)$ & 0.248 & 0.178 \\
CD44 & $44(78.6)$ & $6(10.7)$ & $6(10.7)$ & 1.000 & 1.000 \\
Snail & $31(55.4)$ & $10(17.9)$ & $15(26.8)$ & 0.424 & 0.317 \\
E-cadherin $_{\beta-\text { catenin }^{\mathrm{a}}}$ & $36(64.3)$ & $10(17.9)$ & $10(17.9)$ & 1.000 & 1.000 \\
\hline
\end{tabular}

$\mathrm{P}=\mathrm{M}$, expression of target protein is similar in $\mathrm{P}$ and matched $\mathrm{M} ; \mathrm{P}<\mathrm{M}$, low expression in $\mathrm{P}$ and high expression in matched $\mathrm{M} ; \mathrm{P}>\mathrm{M}$, high expression in $\mathrm{P}$ and low expression in matched $\mathrm{M}$; ${ }^{\mathrm{a}} \beta$-catenin was assessed as normal or abnormal expression, thus $\mathrm{P}<\mathrm{M}$ here means normal expression in $\mathrm{P}$ and abnormal expression in matched M.P, primary tumor; $\mathrm{M}$, metastases.

Table III. Multivariate analysis of independent prognostic factors for overall survival following resection of colorectal liver metastases.

\begin{tabular}{lccc}
\hline Variables & HR & $95 \%$ CI & P-value \\
\hline $\begin{array}{l}\text { Maximum diameter of } \\
\text { liver metastases, cm } \\
\geq 5 \text { vs. }<5\end{array}$ & 3.447 & $1.154-10.041$ & 0.019 \\
$\begin{array}{l}\text { Snail expression } \\
\text { in metastases } \\
\text { High vs. low }\end{array}$ & & & \\
\hline
\end{tabular}

HR, hazard ratio; CI, confidence interval.

both the crucial clinical indicators and the expression levels of Ki-67, CD133, CD44, Snail, E-cadherin and $\beta$-catenin in both primary and metastatic tumors. The results demonstrated that the maximum diameter of liver metastases and Snail expression in liver metastases were independent prognostic factors for OS following resection of colorectal liver metastases. In addition, early $\mathrm{N}$ stage and low CEA expression were associated with longer PFS times. These positive clinical indicators were consistent with previous prognosis score systems (7-10). However, further studies are required to determine the effect of Snail expression in metastases.

The present study is not without limitations. First, only a small sample size was used and limited follow-up were available for primary tumor and liver metastases tissues. In addition, immunohistochemistry analysis (a highly subjective assay) was used to quantify and identify biomarkers. Thus, further studies are required to validate the results presented here.

In conclusion, the results of the present study demonstrated no significant differences in Ki-67, CD133, CD44, Snail, E-cadherin and $\beta$-catenin expression levels between the primary tumor and liver metastases samples. Furthermore, Snail expression may be used as an independent prognostic factor for OS following resection of colorectal liver metastases. Taken together, these results provide a baseline for understanding the consistency and differences between primary and metastatic tumors, as well as the prognostic value of markers in metastases.

\section{Acknowledgements}

Not applicable.

\section{Funding}

The present study was funded by the National Natural Science Fund of China (grant no. 31200975).

\section{Availability of data and materials}

The datasets used and/or analyzed during the current study are available from the corresponding author upon reasonable request.

\section{Authors' contributions}

CL made contributions to acquisition, analysis of data and drafting the initial manuscript. MQ and JYL designed the present study and critically revised the manuscript for important intellectual content. DJ performed the histological examination andensured the quality of pathological evaluation and techniques. CL and MQ confirmed the authenticity of all the raw data. All authors have read and approved the final manuscript.

\section{Ethics approval and consent to participate}

The present study was approved by the EthicsCommittee of the West China Hospital(approval no.2017-169) and written informed consent was provided by patients or their family members prior to the study start.

\section{Patient consent for publication}

Not applicable.

\section{Competing interests}

The authors declare that they have no competing interests. 


\section{References}

1. Stewart BW and Wild CP: World Cancer Report 2014. World Health Organization, 2014.

2. Chen WQ, Zheng RS and Zhang SW: Report of Cancer Incidence and Mortality in China, 2012. China Cancer 25: 1-8, 2016.

3. Garden OJ, Rees M, Poston GJ, Mirza D, Saunders M,Ledermann J, Primrose JN and Parks RW: Guidelines for resection of colorectal cancer liver metastases. Gut 55 (Suppl 3): iiil-iii8, 2006.

4. De Greef K, Rolfo C, Russo A, Chapelle T, Bronte G, Passiglia F, Coelho A, Papadimitriou K and Peeters M: Multisciplinary management of patients with liver metastasis from colorectal cancer. World J Gastroenterol 22: 7215-7225, 2016.

5. Choti MA, Sitzmann JV, Tiburi MF, Sumetchotimetha W, Rangsin R, Schulick RD, Lillemoe KD, Yeo CJ and Cameron JL: Trends in long-term survival following liver resection for hepatic colorectal metastases. Ann Surg 235: 759-766, 2002.

6. Brouquet A, Abdalla EK, Kopetz S, Garrett CR, Overman MJ, Eng C, Andreou A, Loyer EM, Madoff DC, Curley SA, et al: High survival rate after two-stage resection of advanced colorectal liver metastases: Response-based selection and complete resection define outcome. J Clin Oncol 29: 1083-1090, 2011.

7. Yan X, Wang K, Wang Q, et al: Prognostic evaluation of clinical scoring systems for patients undergoing resection of colorectal cancer liver metastases. Chin J Hepatobiliary Surg 21: 388-392, 2015.

8. Spelt L, Andersson B, Nilsson J and Andersson R: Prognostic models for outcome following liver resection for colorectal cancer metastases: A systematic review. Eur J Surg Oncol 38: 16-24, 2012.

9. Nordlinger B, Guiguet M, Vaillant JC, Balladur P, Boudjema K, Bachellier P and Jaeck D; Association Française de Chirurgie: Surgical resection of colorectal carcinoma metastases to the liver. A prognostic scoring system to improve case selection, based on 1568 patients. Cancer 77: 1254-1262, 1996.

10. Fong Y, Fortner J, Sun RL, Brennan MF and Blumgart LH: Clinical score for predicting recurrence after hepatic resection for metastatic colorectal cancer: Analysis of 1001 consecutive cases. Ann Surg 230: 309-321, 1999.

11. Yeung KT and Yang J: Epithelial-mesenchymal transition in tumor metastasis. Mol Oncol 11: 28-39, 2017

12. Mlecnik B, Bindea G, Kirilovsky A, Angell HK, Obenauf AC, Tosolini M, Church SE, Maby P, Vasaturo A, Angelova M, et al: The tumor microenvironment and immunoscore are critical determinants of dissemination to distant metastasis. Sci Transl Med 8: 327ra26, 2016

13. Valastyan S and Weinberg RA: Tumor metastasis: Molecular insights and evolving paradigms. Cell 147: 275-292, 2011.

14. Gao D and Li S: Biological resonance for cancer metastasis, a new hypothesis based on comparisons between primary cancers and metastases. Cancer Microenviron 6: 213-230, 2013.

15. Ho TH, Serie DJ, Parasramka M, Cheville JC, Bot BM, Tan W, Wang L, Joseph RW, Hilton T, Leibovich BC, et al: Differential gene expression profiling of matched primary renal cell carcinoma and metastases reveals upregulation of extracellular matrix genes. Ann Oncol 28: 604-610, 2017.

16. Oakley GJ III, Denning KL, Graffeo V, Griswold DC, Davis AR and Brown LG: Same difference: A pilot study of cyclin D1, bcl-2, AMACR, and ALDH-1 identifies significant differences in expression between primary colon adenocarcinoma and its metastases. Pathol Res Pract 212: 995-1003, 2016.

17. Aprile G, Casagrande M, De Maglio G, Fontanella C, Rihawi K, Bonotto M, Pisa FE, Tuniz F, Pizzolitto S and Fasola G: Comparison of the molecular profile of brain metastases from colorectal cancer and corresponding primary tumors. Future Oncol 13: 135-144, 2017.

18. Zeisberg M and Neilson EG: Biomarkers for epithelial-mesenchymal transitions. J Clin Invest 119: 1429-1437, 2009.

19. Shibue T and Weinberg RA: EMT, CSCs, and drug resistance: The mechanistic link and clinical implications. Nat Rev Clin Oncol 14: 611-629, 2017.

20. Ren F, Sheng WQ and Du X: CD133: A cancer stem cells marker, is used in colorectal cancers. World J Gastroenterol 19: 2603-2611, 2013.

21. Xu H, Tian Y, Yuan X, Wu H, Liu Q, Pestell RG and Wu K: The role of CD44 in epithelial-mesenchymal transition and cancer development. Onco Targets Ther 8: 3783-3792, 2015.

22. Zhang P, Hu P, Shen H, Yu J, Liu Q and Du J: Prognostic role of Twist or Snail in various carcinomas: A systematic review and meta-analysis. Eur J Clin Invest 44: 1072-1094, 2014.

23. He X, Chen Z, Jia M and Zhao X: Downregulated E-cadherin expression indicates worse prognosis in Asian patients with colorectal cancer: Evidence from meta-analysis. PLoS One 8: e70858, 2013.
24. Li LF, Wei ZJ, Sun H and Jiang B: Abnormal $\beta$-catenin immunohistochemical expression as a prognostic factor in gastric cancer: A meta-analysis. World J Gastroenterol 20: 12313-12321, 2014.

25. Kishikawa J, Kazama S, Oba K, Hasegawa K, Anzai H, Harada Y, Abe H, Matsusaka K, Hongo K, Oba M, et al: CD133 Expression at the Metastatic Site Predicts Patients' Outcome in Colorectal Cancer with Synchronous Liver Metastasis. Ann Surg Oncol 23: 1916-1923, 2016.

26. Pitule P, Cedikova M, Daum O, Vojtisek J, Vycital O, Hosek P, Treska V,Hes O,Kralickova M and Liska V:Immunohistochemical detection of cancer stem cell related markers CD44 and CD133 in metastatic colorectal cancer patients. BioMed Res Int 2014: 432139, 2014.

27. Jang TJ: Differential membranous E-cadherin expression, cell proliferation and O-GlcNAcylation between primary and metastatic nodal lesion in colorectal cancer. Pathol Res Pract 212: 113-119, 2016.

28. Buhmeida A, Elzagheid A, Algars A, Collan Y, Syrjänen K and Pyrhönen S: Expression of the cell-cell adhesion molecule beta-catenin in colorectal carcinomas and their metastases. APMIS : acta pathologica, microbiologica, et immunologica Scandinavica 116: 1-9, 2008.

29. Zhang Y, Guan M, Zheng Z, Zhang Q, Gao F and Xue Y: Effects of metformin on $\mathrm{CD} 133^{+}$colorectal cancer cells in diabetic patients. PLoS One 8: e81264, 2013.

30. Horst D, Kriegl L, Engel J, Kirchner T and Jung A: Prognostic significance of the cancer stem cell markers CD133, CD44, and CD166 in colorectal cancer. Cancer Invest 27: 844-850, 2009.

31. Francí C, Gallén M, Alameda F, Baró T, Iglesias M, Virtanen I and García de Herreros A: Snaill protein in the stroma as a new putative prognosis marker for colon tumours. PLoS One 4: e5595, 2009.

32. Gabbert HE, Mueller W, Schneiders A, Meier S, Moll R, Birchmeier W and Hommel G: Prognostic value of E-cadherin expression in 413 gastric carcinomas. Int J Cancer 69: 184-189, 1996.

33. Maruyama K, Ochiai A, Akimoto S, Nakamura S, Baba S, Moriya Y and Hirohashi S: Cytoplasmic beta-catenin accumulation as a predictor of hematogenous metastasis in human colorectal cancer. Oncology 59: 302-309, 2000.

34. Kim W, Kim M and Jho EH: Wnt/ $\beta$-catenin signalling: From plasma membrane to nucleus. Biochem J 450: 9-21, 2013.

35. Kalluri R and Weinberg RA: The basics of epithelial-mesenchymal transition. J Clin Invest 119: 1420-1428, 2009.

36. Kong D, Li Y, Wang Z and Sarkar FH: Cancer stem cells and Epithelial-to-Mesenchymal Transition (EMT)-phenotypic cells: Are they cousins or twins? Cancers (Basel) 3: 716-729, 2011.

37. Fischer KR, Durrans A, Lee S, Sheng J, Li F, Wong ST, Choi H, El Rayes T, Ryu S, Troeger J, et al: Epithelial-to-mesenchymal transition is not required for lung metastasis but contributes to chemoresistance. Nature 527: 472-476, 2015.

38. Danner BC, Gerdes JS, Jung K, Sander B, Enders C, Liersch T, Seipelt R, Gutenberg A, Gunawan B, Schöndube FA, et al: Comparison of chromosomal aberrations in primary colorectal carcinomas to their pulmonary metastases. Cancer Genet 204: 122-128, 2011.

39. Sobottka B, Pestalozzi B, Fink D, Moch H and Varga Z: Similar lymphocytic infiltration pattern in primary breast cancer and their corresponding distant metastases. OncoImmunology 5: e1153208, 2016.

40. Knijn N, Mekenkamp LJ, Klomp M, Vink-Börger ME, Tol J, Teerenstra S, Meijer JW, Tebar M, Riemersma S, van Krieken JH, et al: KRAS mutation analysis: A comparison between primary tumours and matched liver metastases in 305 colorectal cancer patients. Br J Cancer 104: 1020-1026, 2011

41. Harrell JC, Prat A, Parker JS, Fan C, He X, Carey L, Anders C, Ewend $\mathrm{M}$ and Perou CM: Genomic analysis identifies unique signatures predictive of brain, lung, and liver relapse. Breast Cancer Res Treat 132: 523-535, 2012.

42. Wang BB, Li ZJ, Zhang FF, Hou HT, Yu JK and Li F: Clinical significance of stem cell marker CD133 expression in colorectal cancer. Histol Histopathol 31: 299-306, 2016.

43. Passiglia F, Bronte G, Bazan V, Galvano A, Vincenzi B and Russo A: Can KRAS and BRAF mutations limit the benefit of liver resection in metastatic colorectal cancer patients? A systematic review and meta-analysis. Crit Rev Oncol Hematol 99: $150-157,2016$. International (CC BY-NC-ND 4.0) License. 